Supporting information

\title{
Arctic Vegetation Damage by Winter-generated Coal Mining Pollution Released upon Thawing
}

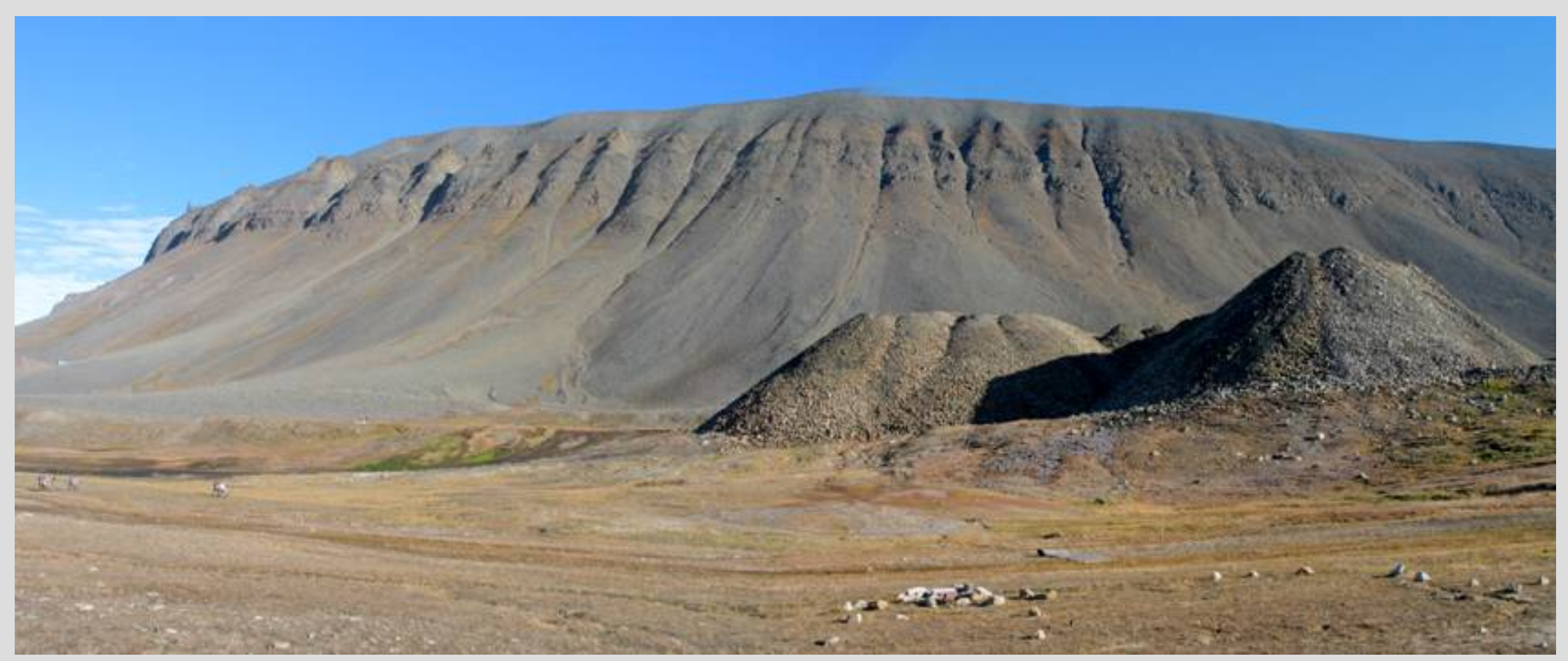

Waste-rock pile in Bjørndalen, august 2004 (Svalbard) 
Supporting information

\section{Arctic Vegetation Damage by Winter-generated Coal Mining Pollution Released upon Thawing}

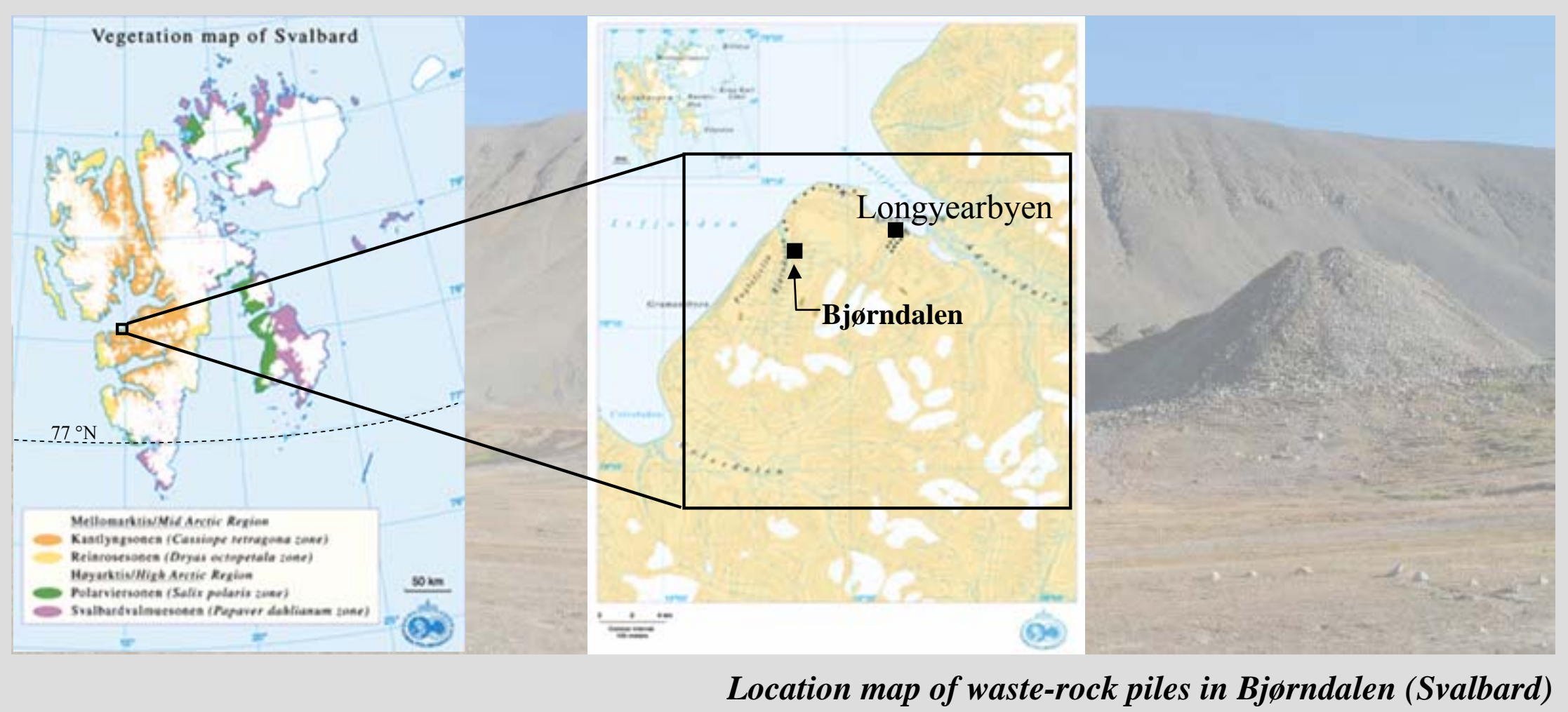




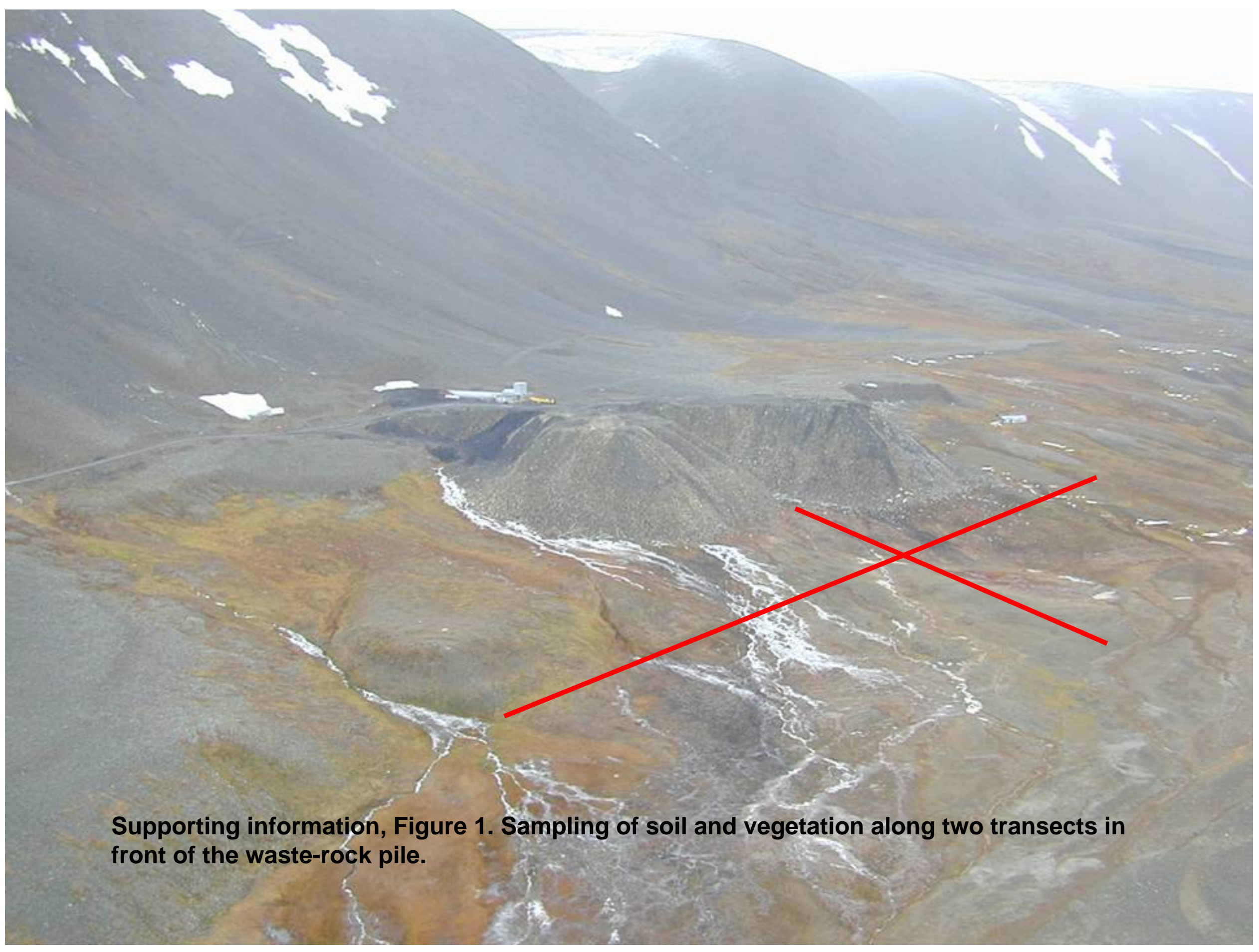




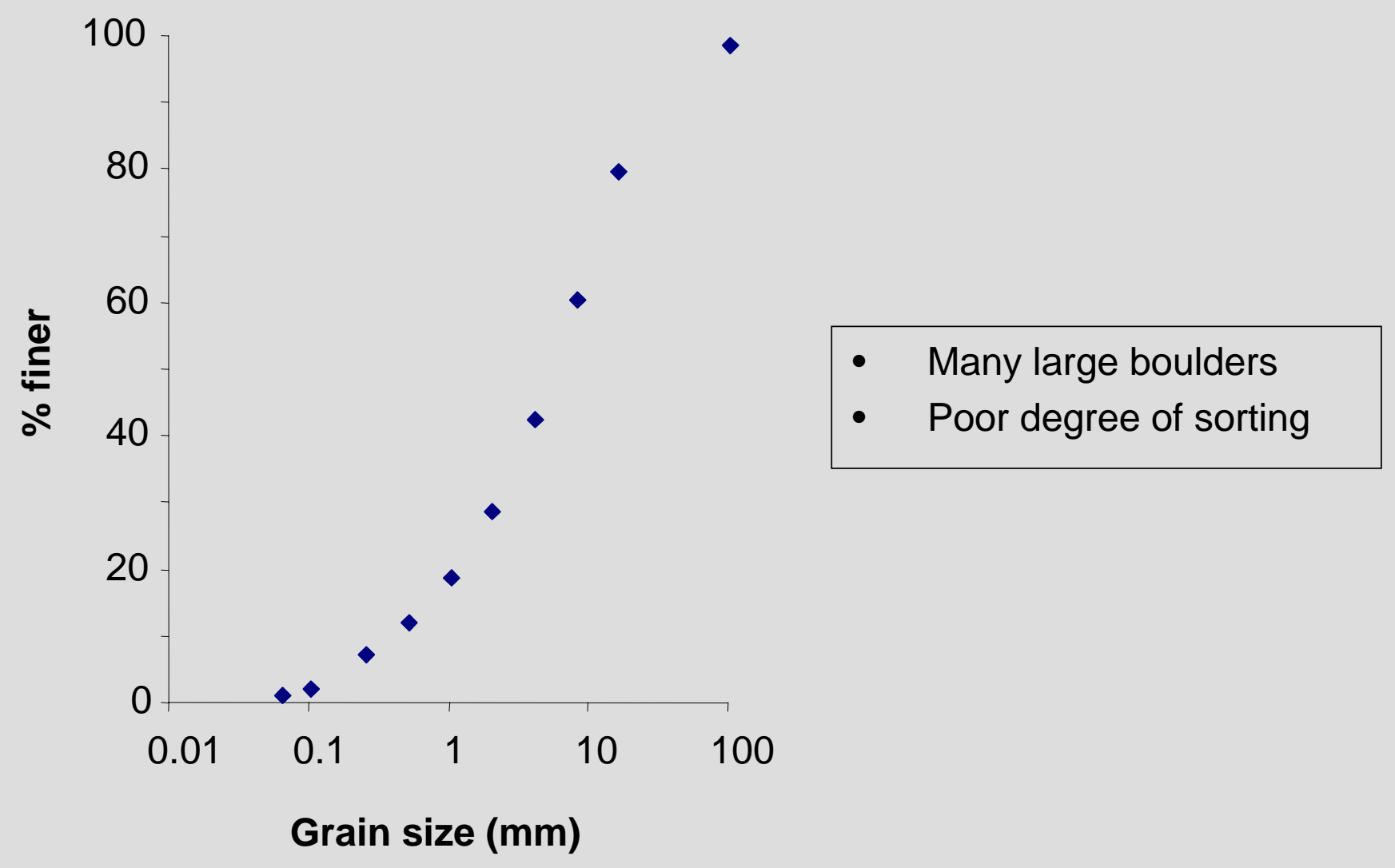

Supporting information, Figure 2. Grain size analysis of waste-rock. 


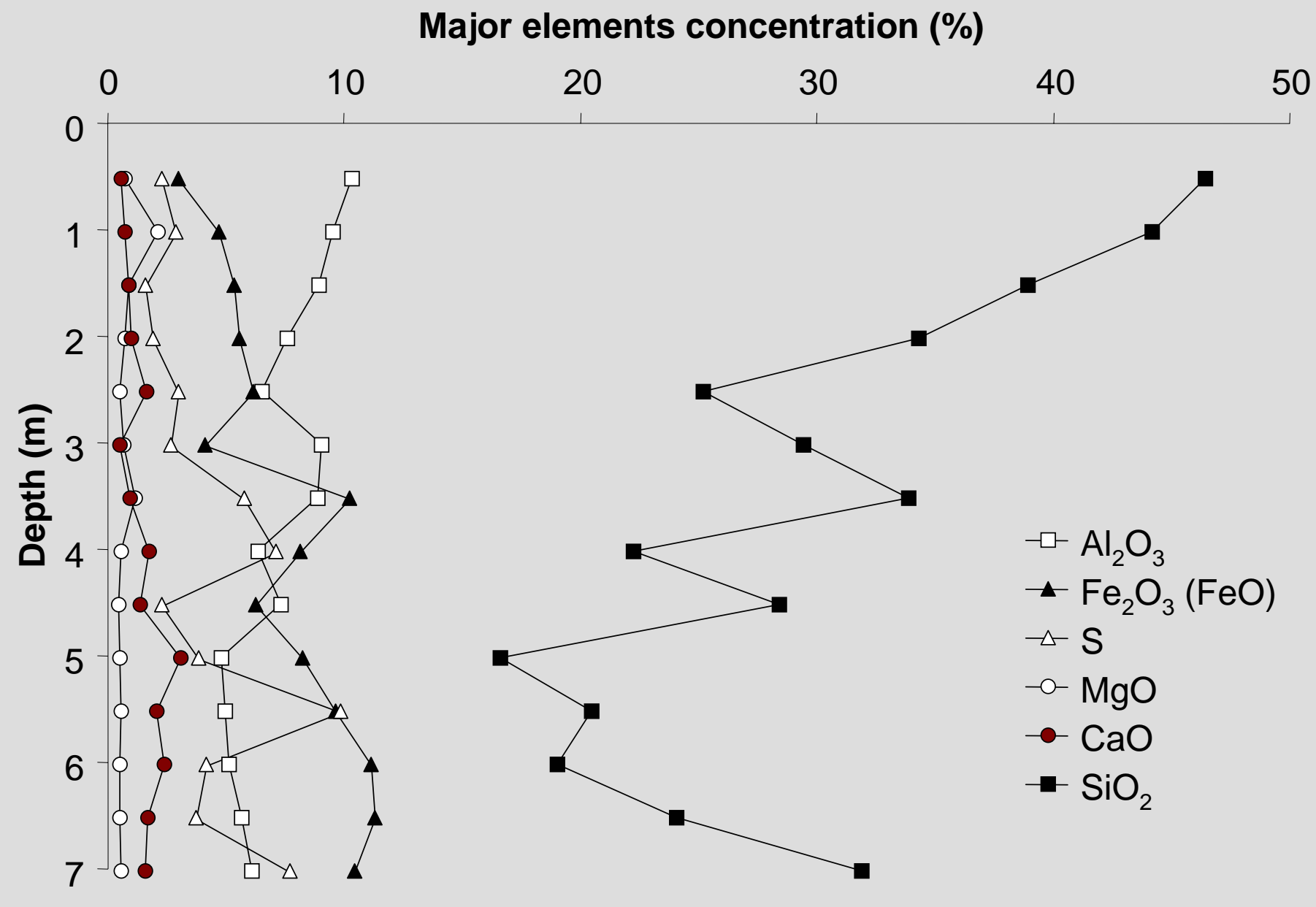

Supporting information, Figure 3. Major element concentrations observed within the waste pile. 


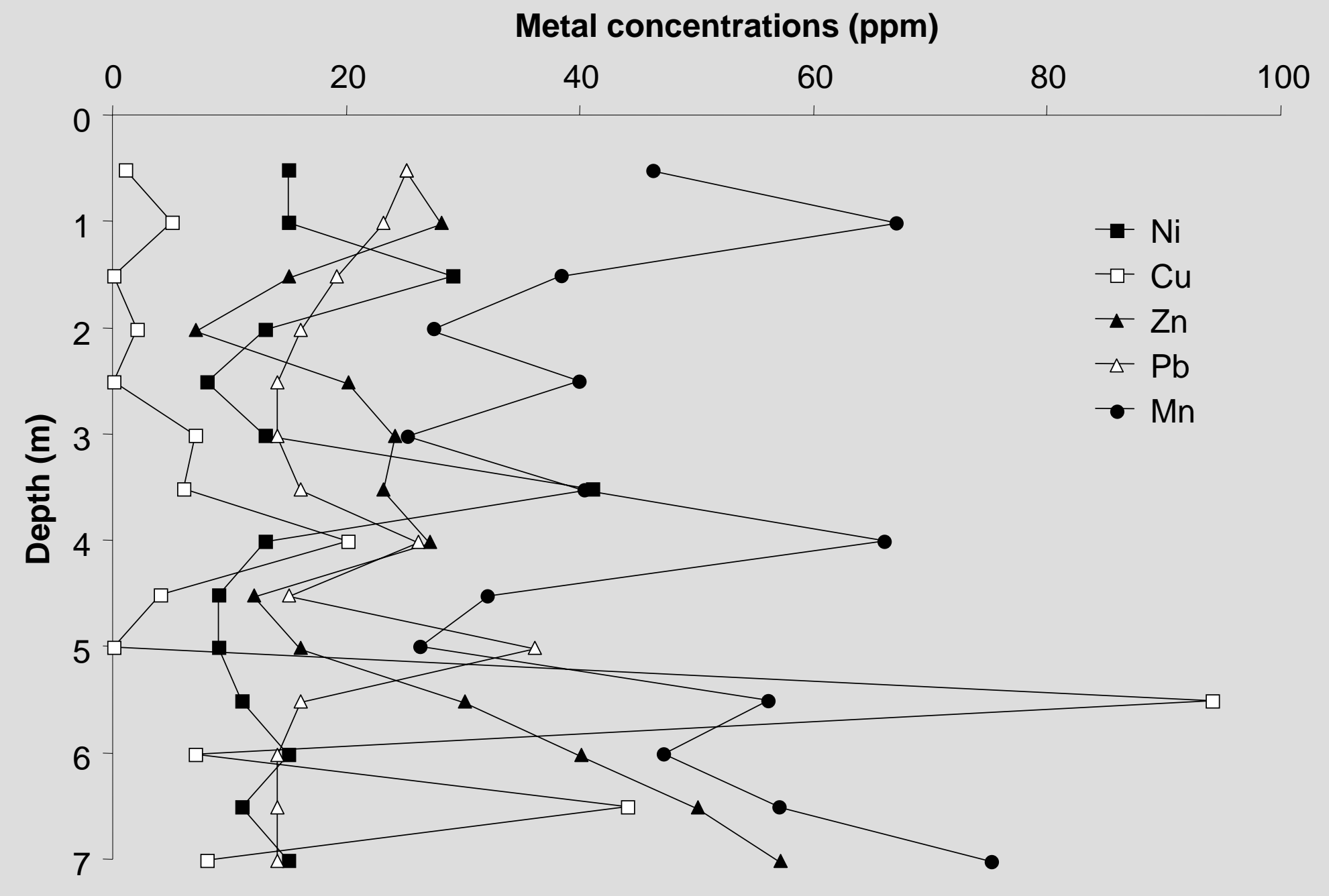

Supporting information, Figure 4. Metal concentrations observed within the waste pile. 

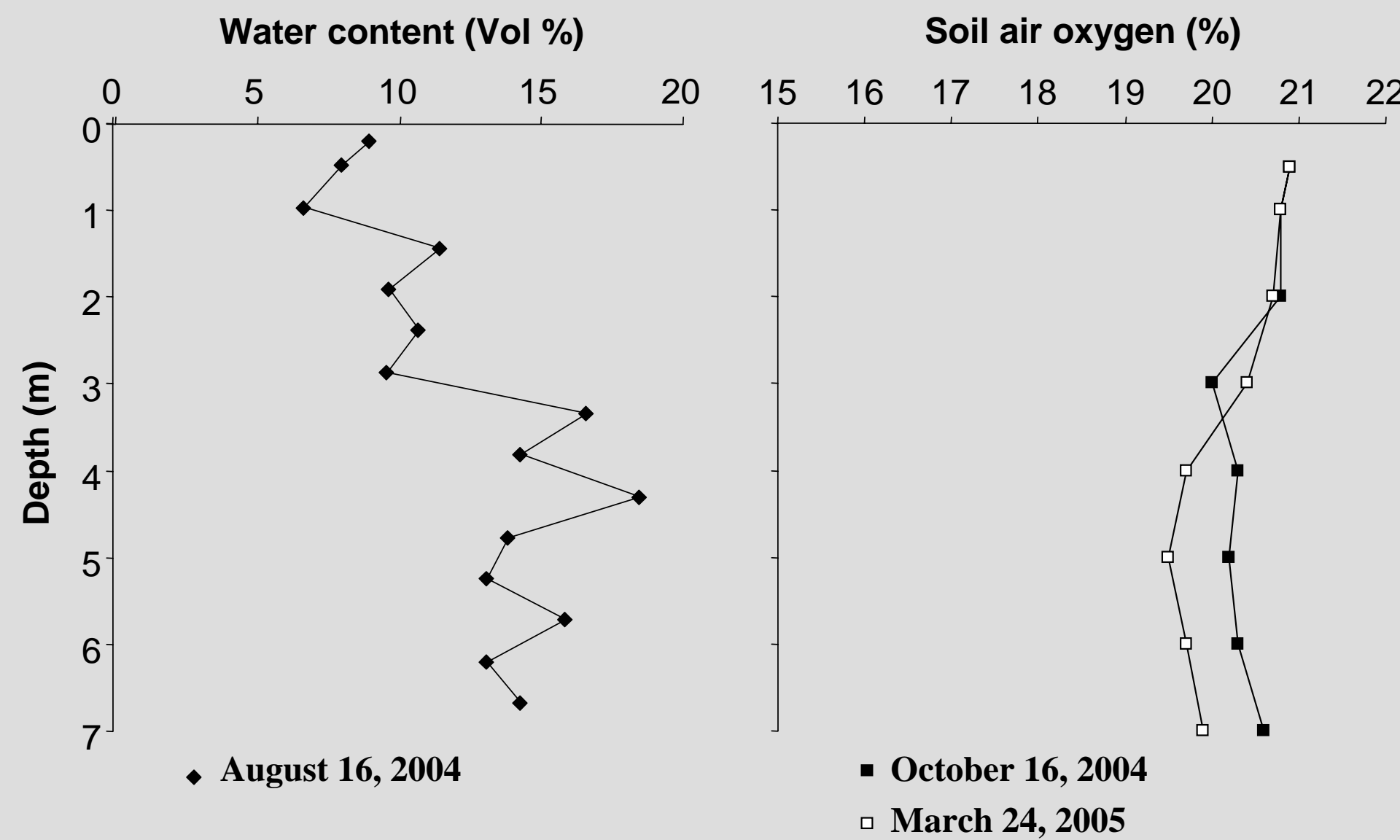

Supporting information, Figure 5. Subsurface water content and oxygen concentrations within the waste pile. 

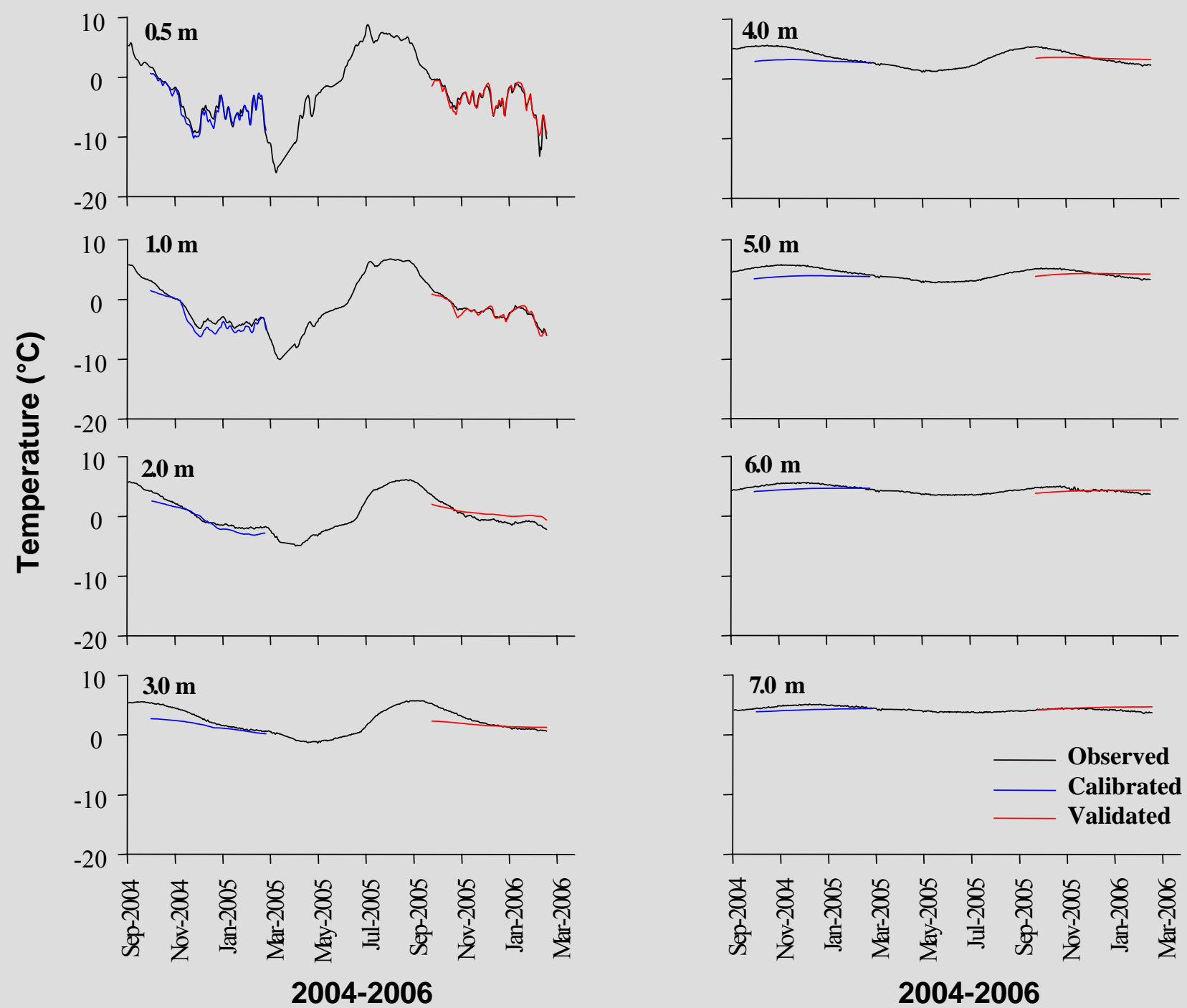

Supporting information, Figure 6. Simulated temperatures in waste-rock pile. The black lines show observed temperatures and the blue and red lines show calibrated and validated temperature, respectively. 


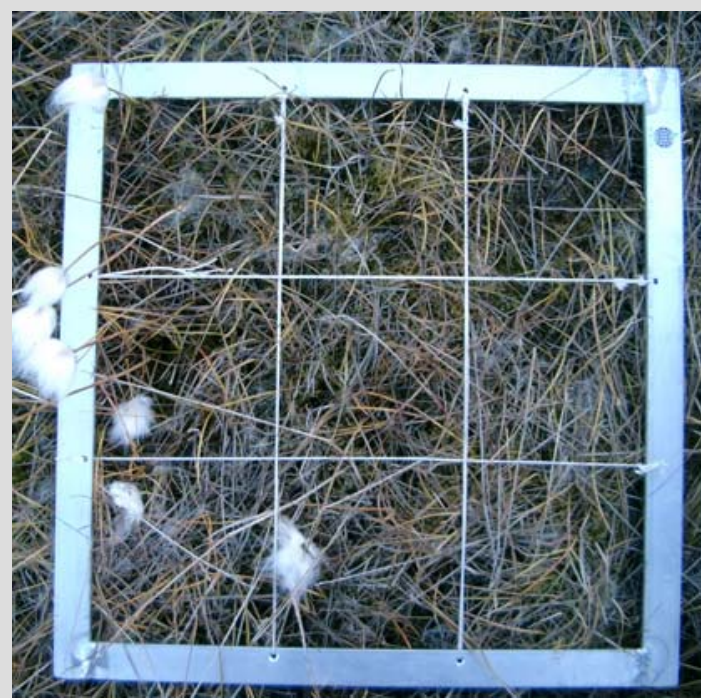

Low impact

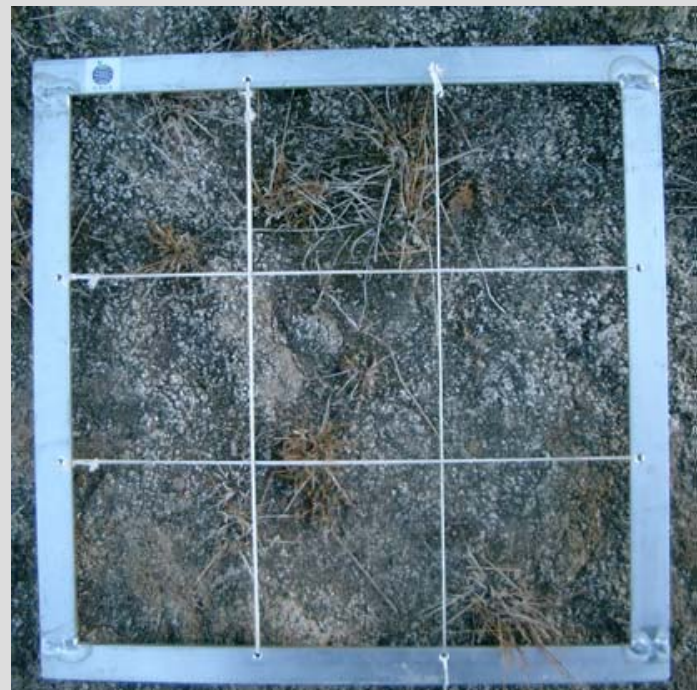

Medium impact

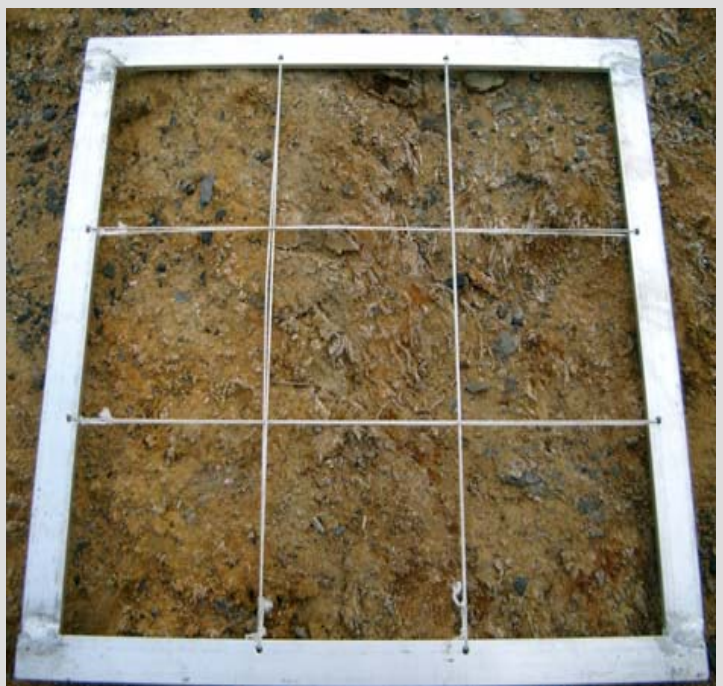

High impact

Supporting information, Figure 7. Vegetation cover and composition. 
- The oxidation of sulphide minerals in the presence of $\mathrm{O}_{2}$ and water produces acid and releases heavy metals:

\section{ZnS}

PbS

$$
\begin{aligned}
& \mathrm{FeS}_{2}+3.75 \mathrm{O}_{2}+0.5 \mathrm{H}_{2} \mathrm{O} \Rightarrow 2 \mathrm{SO}_{4}^{2-}+ \mathrm{Fe}^{3+}+\mathrm{H}^{+} \\
& \downarrow \mathrm{Fe}^{2+} \\
& \mathrm{Pb}^{2+} \\
& \mathrm{Zn}^{2+}
\end{aligned}
$$

Supporting information, Figure 8. Acid Mine Drainage (AMD) production due to pyrite oxidation. 


\section{In an acidic environment $(\mathrm{pH}<6)$ silicate minerals may be weathered and release $\mathrm{Al}$ :}

K-feldspar:

$\mathrm{KAlSi}_{3} \mathrm{O}_{8}+4 \mathrm{H}_{2} \mathrm{O}+4 \mathrm{H}^{+} \rightarrow \mathrm{Al}^{+3}+3 \mathrm{H}_{4} \mathrm{SiO}_{4}+\mathrm{K}^{+}$

Kaolinite:

$$
\mathrm{Al}_{2} \mathrm{Si}_{2} \mathrm{O}_{5}(\mathrm{OH})_{4}+6 \mathrm{H}^{+} \rightarrow \mathrm{H}_{2} \mathrm{O}+2 \mathrm{H}_{4} \mathrm{SiO}_{4}+2 \mathrm{Al}^{+3}
$$

Supporting information, Figure 9. Concurrent silicate weathering (modified from Brady \& Weil, 2002). 
- In an acidic environment extractable manganese on clay minerals and in concretions and cement in shale and mudstone will be released:

$$
\text { Illit } \underset{\mathrm{Mn}^{2+}}{\mathrm{Mn}^{2+}}+4 \mathrm{H}^{+} \rightarrow \text { Illit }{ }_{\mathrm{H}^{+}}^{\mathrm{Mn}^{2+}}+\mathrm{Mn}^{2+}+2 \mathrm{H}^{+}
$$

Supporting information, Figure 10. Concurrent ion exchange processes (modified from Brady \& Weil, 2002). 


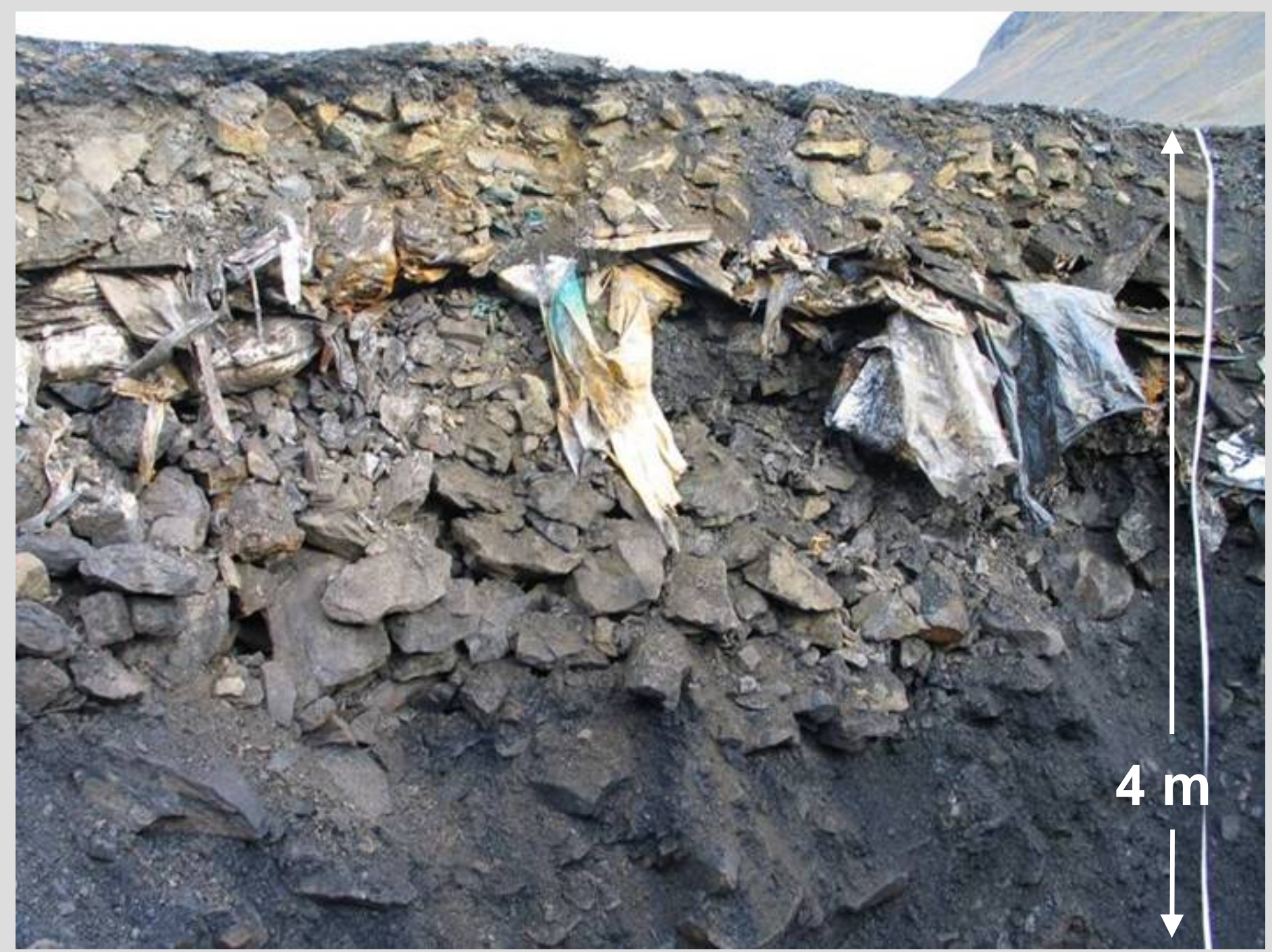

Supporting information, Figure 11. View of a cross-section of the waste-rock pile. 